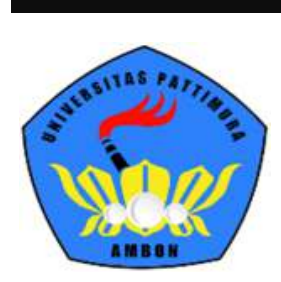

ISSN 2808-2265

Language Studies Centre

Pattimura Excellence Journal of Language and Culture

Journal Home page: https://ojs3.unpatti.ac.id/index.php/pejlac

Journal Email: pejlac.unpatti@gmail.com

\title{
A SEQUENTIAL BLENDED TEACHING MATERIALS: SCAFFOLDING THE NON-ENGLISH LANGUAGE LEARNERS' SCIENTIFIC LITERACY USING ONLINE SOURCES, EDPUZZLE
}

\author{
Hanafi Bilmona \\ Universitas Pattimura Ambon, Indonesia,
}

Article Information:
*Corresponding author
hanafibilmona@gmail.
com
Received March, 10 2021;
Revised April 13, 2021;
Accepted May 20, 2021;
Publication June 1,2021

\begin{abstract}
This study aimed to explore information to support ways on selective teaching materials. The pieces of information for the data were obtained from 44 Students of the Primary Teacher Training Education Department as the sample for this research. The 40 items of statements in questionnaires were designed from a positive point of view and scaled in Likert from; strongly agree (5) to strongly disagree (1). By the content area of two basic research questions concerning Preferences and benefit to the students in applying a sequential blended learning material in teaching English. The data has been analyzed to get meaning using statistic descriptive to denote the average total number of students' responding items of the delivered questionnaires to respondents. from a positive point of view, the result of data analysis found that there was: $4,22 \%$ of students on average responded to the items of questionnaires for more agree and strongly agree to the stated items in questionnaires. the data found that (44 students were found in $4,6816 \%$ in questionnaires that represented preferences (13 items of statements) and 3,7727\% in average found in the statement of questionnaires that represent benefits for 27 items of statements. This data of respondents meant, there was a great number of positive responses toward this teaching approach in parallel, fixing to the two areas: the preferences and the benefit for students as a means to scaffold their other related scientific literacy on the two-part in their learning processes.
\end{abstract}

Key Words: Scaffolding, Blended-Learning, Sequential Teaching Materials.

\section{INTRODUCTION}

It is logical to say that there is no reason to explain any scientific knowledge in detail but is by another or many other different scientific pieces of knowledge. In other words scientifically, any type of knowledge is integrated, such as (Munz 92) to see a piece of knowledge is at least from a "threedimensional" point of view or even from the irrational commitment, means to consideration detail and comprehensively. In essence, integrational teaching activity is considerably more effective. To situate specific content activities of teaching integrally and suitably to the four parts of teaching components, using media, material, method, and management has needed take into account. Even though in each of the four teaching components in a detail scientific sites is not a narrow content area, means each one of all parts has its particular scientific disciplines for comprehensiveness, but, today's technological, computerized development and internet as the most revolutionary invention breaks the barriers, making the world narrow down, and the difficulties access might have changed to be easy access. Participants are only pursuing information by behind monitor screen, virtual reality is formed, and opportunities are not limited by time and space (Drori, Manjikian) in an online (https://www.essaywriting.expert/the-internethas-made-the-world-smaller) This study concerned on an integrational sequence of teaching materials for the non-English language learners (students of primary school teacher education) Pattimura University. 
Integrational sequence teaching material means, the periods of class meeting for general English teaching has been situated following the content area of the other similar previous content material. For instance, the content material such as sentences and paragraphs in the Indonesian language and the sentence construction and short paragraph writing in English. This activity was to guide students practically constructing words to become sentences in various types and to guide students in an outline to focus on paragraph construction, from particular subject area to its focus, to set idea in focus to the representative sentence as the topic, and to guide students to be able to say what s/he wants to say about topic strategically as topic sentence or main idea for a paragraph. Furthermore, develop the logic in a topic sentence into parts for parts of the body of the paragraph for planning to develop the paragraph. From this general English of view, the teaching of English to the non-English language learners should be guided at least into a triangular perspective. To concern on the targeted purpose of teaching English specifically to students on their needs, and the suitable content of materials to fulfill purposeful needs of teaching English, and the level of capacity of student in with their English performance. In other words, English is a language, and it is multidimensionally existing to facilitate transformational information and the development of global scientific knowledge functionally, as a means of scientific communication in sharing information. More than that, the representation of English should have been set up to the thought that the English language is now no longer issued as a foreign language in many countries but is more functionally as International language communication. For that reason, this study aimed to its constructed logic such as in the title, to see the integrational content material sequentially on the teaching of general English to a suitable targeted content area to another similar scientific area of content in the various platform provided on the internet online including sources. One of them (provided platform) is for Edpuzzle.

It is, of course, there are questions regarding the content to which parts of science are. The answer to this question is setting mechanisms. Settings are primarily class activities with students of non-English language learners. With a purposeful orientation to gain information by classroom discussing with students, students were guided in questions for the purpose of finding out information in a quite general content. The content that is mentioning is at least from geographical mapping on where was one originally from, his or her original school, their frequent access to rich town and how, how was the English taught, the teachers from junior to senior high school to junior high school, internet access in their original towns and villages, etc. These all types of information were addressed for the student to simply predicting students' background of English competency from a social and geographical point of view. The questions would be directed to their (students) general situation when being a part in town around campus or when becoming students in elementary school teacher training department (PGSD students). Those are not merely the questions to get information. The last part of the discussion with students was in terms of student's contracted subject materials during the last and in ongoing processes. Information was breaking down from subject area to content area of discussion in each subject. All content of the questions would probably and simply be classified into two, information of students from an external point of view and information of or from students an internal point of view. Information of internal point of view including the last type part of the information regarding a logical thought as the reason why one wanted to learn English, and as such students were guided to recognize internal regulation toward the English language, as one of the subject materials in college curriculum and English as a standard for the fulfillment of a trip of education in university life. This part of the questions has linked to how students consider English to develop their competency in terms of the accessibility of general scientific situations and to open the mind of students in predictably considering the social life of the future personally.

From all ways of approaching the students to the purpose to directing ideas to a more specific focus to set the teaching and learning materials and activities on the target purposes of teaching English for nonEnglish language learners, the aim of this study was set to identify a blended teaching material sequentially in scaffolding the non-English language learner students into two sides, their English language literacy, and their other general linked scientific materials in-class teaching discussion on the 
teaching of English in term of the preferences and benefits for students and to which parts of content on the two different areas. From the approaches, purposes, or intention of students onto the existence of English as one of the subject materials provided in curriculum setting, processes of teaching, and the content of teaching and learning activities. The data as information on purposes of students in learning English or welcomed English as course subject was gained throughout focus group discussion in sharing related questions to students in a primary class meeting at the time. In that term, the conclusion of this focus group activity found that students' learning of English was based on their awareness and to pun on the three basics of their intentions: simply be able to explore ideas or intentions in a simple and shortly communicative English sentence to developing relationships with the English speakers (1), be able to understand short passages in reading and listening of English (2), and be able to develop their personality to thinking of the future in terms of considering global scientific development whether in an on or offline. The second option of students' point of that intention has covered also one of the prerequisite requirements of almost all universities and including Pattimura University in the final process of paper examination with an administrative need of particular standard TOEFL Prediction test certification.

This study was set up on its theoretical foundation of $S-R$ under the behaviouristic paradigm, which means to stimulate students by provided or serving them in specific activities and teaching materials to see the respond behaviorally from day-to-day activities. It was quite difficult to cover students in personal need, in a different social and cultural background, however, this was an effort to minimize the gap in the need of students in particular similar scientific ready material in English using video. The effort is at least in line with (Lioyd (2000:133) in (Wearmouth et all. 2005:6) "Educational equity requires an educational strategy which response to individual differences to promote at least satisfactory levels of development and achievement." Besides, there has been suggestive effort internationally referenced by the UK and New Zealand in the case of policy and practical activities in responding to the needs of students from diverse cultural backgrounds, (Wearmouth et all. 2005: viii, in the preface).

Edpuzzle is the name of one of the features, an online platform. Edpuzzle provides any type of videos, such as in YouTube and usually linking to YouTube. when the site is linked, the video is almost equal in both. In case, there are different even linked one another. This is because video the provided video in YouTube be sometimes modified in particular parts to the purpose of teaching and learning activities. Any part of videos in Edpuzzle is normally medicated in pause to set question, to get clarification of some stressed point, etc., following to which purpose the content of a talk becomes highlighted points. Sometimes the video of teaching materials in Edpuzzle was created in own creativity means not been taken from any site on YouTube. Types of teaching materials, the video in this platform is, however, but every video is guaranteed in its quality, using scientific knowledge. This is because designed and medicated teaching materials is from the result of the creativity of almost experienced teachers, the expert from any sites of the world openly. The inexperienced teacher may become a member of this site by registered him or herself as a member to be able to directly access some ready materials from this platform, Edpuzzle.

Considering the quality of material in the form of video in this online platform, the term sequential proposed to the first word in the sentence of the title of this writing, represents the meaning of a process. A process of teaching that is not away from a set of planning by identifying any scientific material of student in any subject that has been thought or at least the chosen English material on video is in the principle to proceed other scientific literature. This principle as the need was because, the purpose of teaching students general English was for developing students' scientific literacy to the two different areas, English language wits own specific competency, and scaffolding any other different related scientific knowledge to become more literate strengthened, and sustained in their field area during the process and hope for the futures. (Axford et all. 2009: xv) in a program for Parents as Tutors in scaffolding Literacy An integrated and sequential approach in teaching reading, spelling and writing argues that "through the Scaffolding Literacy teaching sequence, even the most reluctant readers/writers can be assisted to read with more fluency and comprehension, and write with more imagination and 
gusto". While, a different program concerning integrated content-based teaching materials, (Stephen et all.1997:57) define the objective is to "the development of multiliteracy, defined as "the pursuit of intellectually challenging and culturally broadening activities in more than one (for instance) language". Stephen et all, add in a different part, this kind of teaching using language, "currently very common in ESL and English as a Foreign Language (EFL) classes around the world, are now offered in many foreign language programs as well" (ibid). Stephen et all in the other part adopt SJ and HC that "content-based instruction, teaching language skills in a way that is very relevant to these college students, they watch, told to listen, explore ideas, etc., "they were required to use first their bottom-up language processing, and then their top-down, both of which are necessary to properly digest an academic lecture. (SJ, ns)10". Heriyawati et all state, "The curriculum in this course are content-based uses materials from various academic disciplines in the form of real UCLA reading assignments and lectures. A typical exercise is to have the students watch a videotape of a real university lecture by a professor and use the lecture to carry out various learning exercises." Vol.9, No. December 2014) while, Hiebert and colleagues (2002), ... to help "transform practitioner's knowledge into professional knowledge by making information about literacy coaching public, storable, and share-able, thereby contributing to the promise of verification and improvement of practice". (in Heriyawati).

\section{RESEARCH METHODOLOGY}

\subsection{Material}

In a quantitative research study, this research was based on a positivistic paradigm (knowledge is unproblematic)) to conduct a quick and small-scale study that provides practical results for short terms gathering and analyzing the data (Newman 2007: 18), to reflexively considering students' situations from complex variety backgrounds in particular different characters in Urban borders, isolated, and un-isolated towns and villages over the Islands around the area in Maluku and out of Maluku. The data in this study was "...computing statistic by taking appropriate averages over the scores of all available subjects", (Andreas van der Ark et all. 2005: 127). The questionnaires comprise forty (40) questions addressed to 44 students in the department of elementary school teachers (students of non-English language learners PGSD), in a public or general English faculty of teachers training and educational sciences. Questionnaires were designed in a positive point of view to which tended to explore information as data in terms of the benefits and preferences of students in teaching English providing readily used materials in the form of English-speaking videos provided on the internet online, the Edpuzzle, and YouTube, an adaptive way to scaffolding the non-English language learners' scientific literacy and the English subject in periodical meeting sequentially. Lists of 40 statements for Questionnaires were set up into Likert Scale in five-level categories orderly to have information from: Strongly Agree (5), Agree (4) Less Agree (3) Not Agree (2) and. Strongly Not Agree (1) into two areas, from the preferences and benefits for students in that online gained teaching approach to video materials. The content area of the statements in questionnaires aimed to explore information in regards to the area of like-dislike, hope-expectation questionnaires option no. 1 to 5, personal recognition of students' English competency questionnaires option no. 6 and 7, historical condition toward students learning of English in Junior and Senior high school questionnaires option no. 8 to 14, personal recognition towards the need of English in the today's world work questionnaires option no. 15 to 20, and questionnaires option no. 21 to 40 cover the area of benefit of learning English using particular ready served materials from online in Edpuzzle and YouTube.

\subsection{Data Analysis}

Throughout the of the covering data of students' responses, data would have analyzed using descriptive statistical analysis for meaningful data as a conclusion to see the average total number of 
students response in terms of the benefit and preferences for the teaching to scaffolding students' scientific literacy in two different are, for their English and other scientific pieces of knowledge.

\section{FINDINGS AND DISCUSSION}

Considering that this data concerned two parts, in terms of preferences of students and the benefit of learning, the analyzed data found that in general, $4,22 \%$ of students who responded to the items of questionnaires responded more agree and strongly agree to the statements of questionnaires. This average total number of the respondents in one side, 44 respondents were identified in $4,6816 \%$ in questionnaires that represented variables on questions in the area of preferences (13 items of statements). While in the other side, $3,7727 \%$ on average identified in the questionnaires that represent the area of information for the benefits ( 27 items of statement) on implementation of the teaching using the ready served material on English speaking videos provided online. For the detailed data of the respond of students, such as presented in the following two table data below, data to represent students respond in benefit and preference.

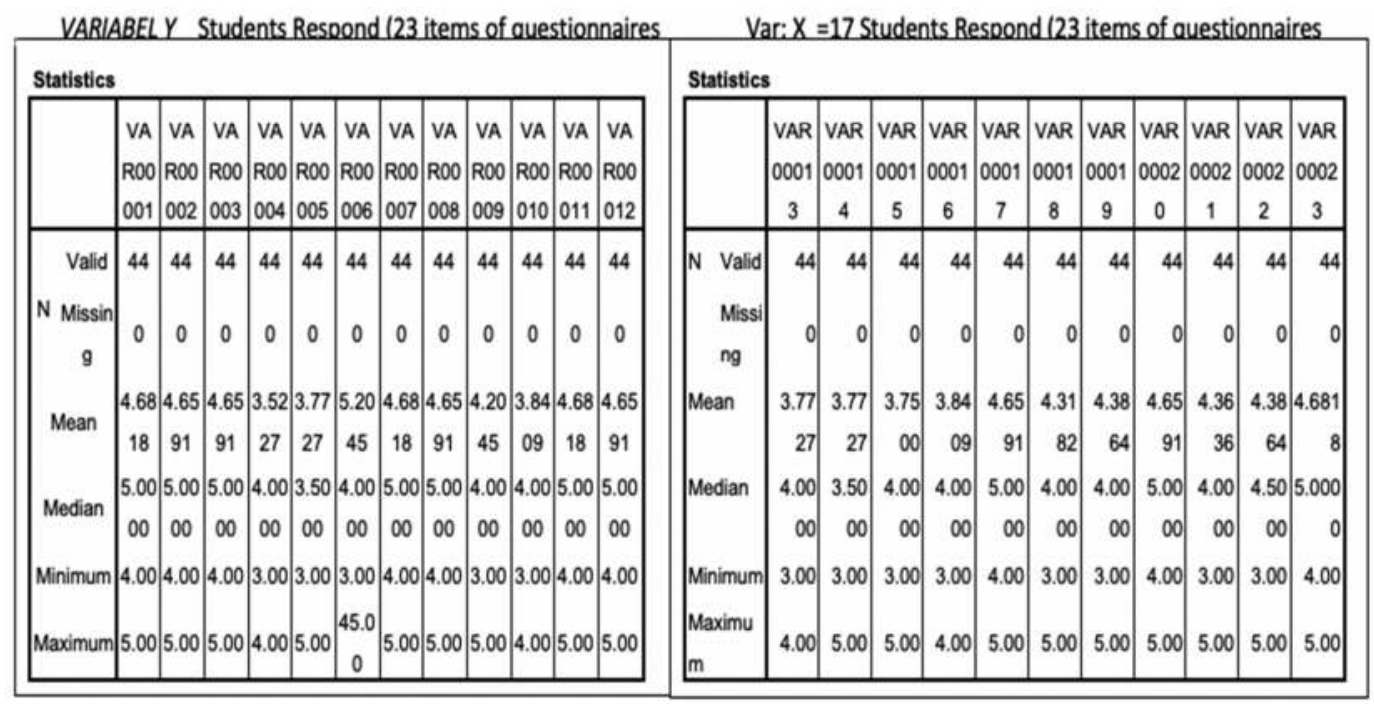

The data of findings means that there were acceptable, suitable, and meaningful results in applying the teaching of general English using readily provided materials through video. There were some points highlighted in the area of the research such as: 1/ students realized their personal capacity in English and they wanted to be progress, $2 /$ even the questions and content target did not cover particular are in detail, but be concluded that the low capacity of students in English was mainly caused by ineffective setting management when they were in junior and senior high school subjected to students' demotivate to learning English, 3/ everyone realize the effect of being unqualified in English in today's world work in terms of challenging, 4/ the approach to teaching English using some related ready teaching material can be scaffolding student in two ways, English teaching and learning and their previous general related scientific discussed material in their field area, 5/ in English, this approach benefits students in two parts, vocabularies, and content, while it also provide freeness, enjoyability, easiness, listening and many others without limited in time and available in any situation. While, in different scientific pieces of knowledge, it also scaffolds students in new vocabularies listening and enjoying, recycling of vocabularies in previous materials other scientific disciplines, and wider understanding of content and the details. In the end, 
teaching general English by blending materials, the ready served material in videos is supposed to be effective in scaffolding students' literacy in particular skill and competency and much other scientific literacy for students of the non-English language learning.

In the part of reflection accessible online, the learning goals of students be progressed in selfawareness towards their styles of learning, because good learning style of students can be reflecting their maximal effort and resulting to the achievements and personal management, reflecting of an abstract of Journal Ilmiah Didaktika Vol.20, No. 2. 2020 in https://jurnal.ar-raniry.ac.id/index.php/didaktika/ article/view/5229. Students in sample data of this study had been treated in a specific living situation regarding the limited access in particular character oh hometown and villages in the area of Maluku archaeologically. This situation of students affected their English competencies, of what to be internalized as findings in those as sample area in item no. 1 to 5, and reflexing to question item 6 and 14 regarding students personal and group discussion related to their historical situation. Even though those types of students had their hope, but they were limited in isolation of information, financial, ethic and culture, etc. In this situation, (Silins \& Milford 2008) have "describe a school environment that supports low-income student success as one where there are professional relationships that promote trust and cooperation". On the other side, (Henderson and Mapp 2002) also synthesized research showing that families of cultural background, education, and income levels can often do have a positive influence on their children's learning", such as those options of questions no. 15 to 20 in (Krisin E Grayson 2020) accessible in online: https://www.idra.org/resource-center/serving-low-income-students/, this situation, students sometimes looked to hide parts of information related to their cultural setting. Damon 2002) in (Smagorinsky and Texel 2005: 42) says the item of questions no. 21 to 40 that served to respondents were more to benefit and few items of questions only represented the case of preferences of students, and value ethical core not merely subjective preference like enjoying music or taste the clothes but universal validity claims personal collective conscience (imid).

To scaffolding students' literacy, Cook Hiral, 2019 says, a teacher should "building captivating anticipatory sets for lessons not only motivates students to participate, but also keeps them engaged throughout the lesson, accesses their prior knowledge, scaffolds information (E11), builds their academic language, and facilitates the acquisition of new knowledge" (37). In this case, a teacher should scaffold students in sources and information from their prior knowledge, Cook Hiral (2019: 128). Debra L et all (2019:105) state, In teaching writing to high school students we have noticed a trend that emulates that of reading: students read less, therefore comprehend less, and consequently write less and are less able to write well" this statement gives an essence as if, that all situation all experiences identified for students in pursuing the data, more or less but things caused also by the prior teaching activities. This information represents some general part of questionnaires in option 21 to 40, in terms of students scientific information on their English capacity, equals to Elisa Bertoldi (2019) states that the two factors more effect students of English as L2, Limited time to run the activities and motivation as she cited (Cameron 2001) to remark that motivation to learn a foreign language is not as strong for children as it is for their native language, accessed in online in: (https:/www.researchgate.net/publication/ 333669823 Online resources for teaching English as L2.

\section{CONCLUSION AND SUGESTION}

As the conclusion of this study, there are some points in which the situation and the data related to the research area and the students of Primary Teachers Education Department, those who have taken for sampling for research data.

a. The student in this department were found to be originally from the area around Buru Island (north and south), Seram Island (east, central and west), Key/Souths Maluku, Aru Archipelagoes Island, and separated area around Southwest Maluku, and around Ambon Island and rarely those who from 
out of Ambon area. These students were from a variety of different cultures and backgrounds, but unfortunately equal in English competency they belong to and were supposed to be at a low level.

b. In an approach of teaching their public English language as course subject using particular ready served English material, the Videos providing in online consequently, to scaffold their English of particular purposes and other related scientific literacy seemed to one of the approaches fixing to students' preferences and the intention of benefits. This idea is according to the situation in which students were responding to all 40 items of questionnaires in the total such as in the data findings, and some facts on short explanations. It was shortly and simply to say, easy in implementation, simple, but useful for class teaching.

c. The today's teaching activities has a tremendous need to situate and adapt and adapt to the way of teaching activities known as blended learning in its very huge and open interpretation to the activity.

In considering the using the simple teaching approaches mention in almost all parts before, the suggestion seems to be mainly to the teachers and the researchers. The first suggestion is to the teachers as the actor in education, the suggestion is that today's education has needed to be mixing up materials addressed on an Internet-linking activity as a means of enriching the sources materials. This is because the Internet provides almost all sources material from the level of novices to the experts' part in level. This suggestion is also based on the thought that generation in category for Millennials, their life is the life with technology and online. Therefore, teaching activities need to situate and adapt to their life to make things go smoothly to the proposed target. While suggestions for researchers have addressed the three points. First, this research was conducted to quite low total numbers of respondents so that, the result is still too curious to be generalized in a complex and ferity characters of the respondent. Second, this study was conducted in the location of class teaching, there might be the meaning of subjective logic mainly on the respondents in responding items or questionnaires because this data was gained from the data that was supposed to be an internal activity between a teaches and his students internally in a class teaching activity. This was, even though the data was taken in a secret situation, the situation in which the researcher had tried as he could to keep the rigid information. The process of gaining the data processes was designed as if not for data research, but more for the data of a pre-evaluation of a class teaching. Third, the questionnaires did not set up specifically directed to particularly detailed information. This research instrument still covers general data information. The further researcher needs to concern with the setting for the detail more comprehensively.

\section{REFERENCES}

Axford et all. (2009) Scaffolding Literacy an Integrated Sequential Approach to Teaching Reading, Spelling, and Writing. ACER Press, an imprint of Australian Council for Educational Research Ltd.

Bertoldi, Elisa (2019) Online Resourses for teaching English for L2, in: (https://www.researchgate.net/publication/333669823 Online resources for teaching English as L2.

Cook, H. et all (2019) Academic/language Literacy Strategy for Adolescent A "How to" Manual for Educators. Routledge Madison Ave, New York, NY 10016. Expert Writing Service. Accessed in online: https://www.essaywriting.expert/the-internet-has-made-the-world-smaller-essay/

Trevino, Jessi. S. "IDRA" Vol. 211 . Mey 18 2021. Retrieved from https://www.idra.org/resourcecenter/serving-low-income-students/. 
Journal Didaktika Pendidikan. Vol. 20. No.2 ISSN- L2355-6129. 2020, pp. 126-142. Retrieved from https://jurnal.ar-raniry.ac.id/index.php/didaktika/article/view/5229.

Andreas van der Ark, L et all (2005). New developments in Categorical Data Analysis for the Social and Behavioral Sciences. Lawrence Erlbaum Associates, INC., Mahwah, New Jersey 07430.

Munz, Peter (1996) Philosophical Darwinism on the Origin of Knowledge by means of Natural Selection. Routledge, 11 New Fetter Lane, London EC4P 4EE.

Newman, L (2007) Basic of Social Research Qualitative and Quantitative Approaches. Pearson Education, INC.

Smagorinsky, P. and Taxel (2005) The Discourse of Character Education Cuture Wars in Classroom. Lawrence Erlbaum Associates, Inc., Publishers.

Wearmouth et all. (2005) Perspective on student's behaviour Exploring theory and Developing Practice. British Library Cataloguing in Publication Data, Tylor, ISBN 0-415-35401-3 